\title{
Rationalising the use of investigation for urinary tract infections: Analysis of 700 patients and proposal for a diagnostic algorithm.
}

\author{
Ibifuro Dokubo ${ }^{1}$, Felicity Reeves ${ }^{1}$, Sophia Cashman $^{1}$, and Vincent Gnanapragasam ${ }^{1}$ \\ ${ }^{1}$ Cambridge University Hospitals NHS Foundation Trust
}

November 1, 2020

\begin{abstract}
Aims: To evaluate the diagnostic yield of investigations performed on patients with a history of urinary tract infections (UTI). Methods: A retrospective review was conducted on patients who underwent cystoscopy and imaging for a history of UTI between 2014-2019 in a single UK teaching hospital. Data was collected on demographics, cystoscopy and radiological findings requiring further management. The cohort was stratified by age, gender, and a confirmed history of recurrent UTI (rUTI). The subsequent algorithm was re-tested in a second cohort to validate its use. Results: 700 patients were included in the primary analysis, 427 female and 273 males. 331 meet the criteria of rUTI. The median age was $64 \mathrm{y}(18-97)$. Imaging abnormalities were equally frequent in males $6.3 \%(15 / 241)$ and females $8 \%(30 / 380)$ and the majority noted in patients aged [?]55y, 30/45(66.7\%). Amongst those who did not meet the definition of rUTI, abnormal imaging was identified in 5-7\% regardless of age group and gender. Cystoscopy abnormalities $(\mathrm{n}=24)$ were twice more likely in males, 5.5\%(15/273) than females, 2\%(9/427). 88\%(21/24) were identified in patients [?]55y. There were no positive findings in women $<55 \mathrm{y}$. Applying baseline imaging but confining cystoscopy to those aged [?]55y and men with a confirmed history of rUTI would have saved $44 \%$ of procedures, missed no abnormalities with an overall diagnosis detection rate of 9.8\%(69/700). This algorithm was validated in a separate cohort of 63 patients; applying it would have saved 46\%(29/63) of cystoscopies with a positive diagnostic rate of $9.5 \%$ and no missed findings. Conclusion: To our knowledge this is one of the largest studies reporting the outcomes of investigations for UTI and rUTI. Our result suggests that imaging is a useful baseline assessment, but cystoscopy should be limited to specific subgroups. We propose and validate a simple decision algorithm to manage investigations for referrals for UTI in secondary care.
\end{abstract}

\section{Hosted file}

Main document.pdf available at https://authorea.com/users/372023/articles/490178rationalising-the-use-of-investigation-for-urinary-tract-infections-analysis-of-700patients-and-proposal-for-a-diagnostic-algorithm

\section{Hosted file}

Figure 1final paper.pdf available at https://authorea.com/users/372023/articles/490178rationalising-the-use-of-investigation-for-urinary-tract-infections-analysis-of-700patients-and-proposal-for-a-diagnostic-algorithm

\section{Hosted file}

Table 1 UTI investigation paper.pdf available at https://authorea.com/users/372023/articles/ 490178-rationalising-the-use-of-investigation-for-urinary-tract-infections-analysis-of700-patients-and-proposal-for-a-diagnostic-algorithm

\section{Hosted file}


Table 2 UTI investigation paper.pdf available at https://authorea.com/users/372023/articles/ 490178-rationalising-the-use-of-investigation-for-urinary-tract-infections-analysis-of700-patients-and-proposal-for-a-diagnostic-algorithm

\section{Hosted file}

Table 3 UTI investigation paper.pdf available at https://authorea.com/users/372023/articles/ 490178-rationalising-the-use-of-investigation-for-urinary-tract-infections-analysis-of700-patients-and-proposal-for-a-diagnostic-algorithm

\section{Hosted file}

Table 4 UTI investigation paper.pdf available at https://authorea.com/users/372023/articles/ 490178-rationalising-the-use-of-investigation-for-urinary-tract-infections-analysis-of700-patients-and-proposal-for-a-diagnostic-algorithm

\section{Hosted file}

Table 5 UTI investigation paper.pdf available at https://authorea.com/users/372023/articles/ 490178-rationalising-the-use-of-investigation-for-urinary-tract-infections-analysis-of700-patients-and-proposal-for-a-diagnostic-algorithm 